\title{
Effect of Colostrum on the Symptoms and Mucosal Permeability in Patients with Irritable Bowel Syndrome: A Randomized Placebo-controlled Study
}

\author{
Jin Young Yoon, Soo Jung Park, Jae Hee Cheon \\ Department of Internal Medicine and Institute of Gastroenterology, Yonsei University College of Medicine, Seoul, Korea
}

Irritable bowel syndrome (IBS) is defined by the presence of abdominal discomfort or pain associated with altered bowel habits with symptoms of constipation and/or diarrhea. ${ }^{1}$ IBS affects up to $16.8 \%$ of the general population in Korea. ${ }^{2}$ Standard treatment of IBS that primarily aims for symptom relief, has not yet been established. The pathogenesis of IBS appears to be multifactorial, which involves altered gastrointestinal motor function, enhanced perception of visceral stimuli, and psychosocial factors. A role of enteric mucosal immune activation has been recently suggested. ${ }^{3,4}$ Endotoxin, a component from the outer membrane of gram negative bacteria, stimulates various inflammatory mediators, such as cytokines (e.g., tumor necrosis factor) and acute phase reactants (e.g., CRP). Inflammation leads to elevated blood endotoxin levels as a result of increased intestinal permeability due to intestinal mucosal damage. ${ }^{5}$ Patients with IBS have elevated endotoxin levels, which proves that IBS is associated with microscopic inflammation of the enteric mucosa. ${ }^{6}$ Colostrum, which is produced by female mammals immediately after giving birth, is a nutrient-rich fluid that contains immune, growth, and tissue repair factors. ${ }^{7}$ Colostrum contains a significant amount of complement components that act as natural anti-microbial agents to actively stimulate the maturation of an infant's immune system. Bovine colostrum, a raw material for immune milk preparations, can be used to treat or prevent infections of the gastrointestinal tract. ${ }^{8-10}$ The objectives of this study were to analyze whether the admin-

Received December 23, 2013. Revised December 23, 2013

Accepted December 23, 2013.

Correspondence to Jae Hee Cheon, Department of Internal Medicine, Yonsei University College of Medicine, 50 Yonsei-ro, Seodaemun-gu, Seoul 120-752,

Korea. Tel: +82-2-2228-1990, Fax:+82-2-393-6884, E-mail: geniushee@ yuhs.ac

Financial support: None. Conflict of interest: None istration of bovine colostrum could relieve all symptoms of IBS (using several scoring systems to monitor IBS), and could lead to a decrease in endotoxin levels in patients with IBS (by measuring the endotoxin level before and after administration).

This study was a prospective, double-blind, randomized, placebo-controlled trial to analyze the efficacy of bovine colostrum. Patients with IBS (aged, 18-80 years) were voluntarily recruited. They were selected according to the ROME III criteria, which was the occurrence of recurrent abdominal pain or discomfort for at least 3 days per month in the last 3 months associated with 2 or more of the following: (1) relieved with defecation; (2) onset associated with a change in frequency of stool; (3) onset associated with a change in form or appearance of stool. ${ }^{11}$ Patients were randomly classified to either the colostrum or placebo group. A sample of bovine colostrum ( $15 \mathrm{~mL}$; $\mathrm{MuKoBa}^{\mathrm{TM}}$, Seoul, Korea) was orally administered once daily before breakfast. All the physical characteristics of bovine colostrum (e.g., smell, color, taste, volume, and packaging) were indistinguishable from the placebo (artificial milk).

The 8-week study included a 4-week treatment period and a 4-week follow-up observation period without treatment. Clinic visits were conducted at weeks 0,4 , and 8 , while phone interviews were performed weekly. Three scoring systems of IBS were used for the evaluation of symptom relief to measure the primary efficacy of colostrum. The first scoring index was assessed by using the IBS Global Improvement Scale (GIS) with the patients' rating their overall satisfaction with their IBS treatment on a 7-point Likert scale, ranging from "very unsatisfied" to "very satisfied". ${ }^{12}$ Data were collected weekly by using an interactive voice-response telephonebased system. The second scoring index used was the Gastrointestinal Symptom Rating Scale (GSRS-IBS), which was a short and user-friendly instrument with excellent psycho-

๑ Copyright 2014. Korean Association for the Study of Intestinal Diseases. All rights reserved.

This is an Open Access article distributed under the terms of the Creative Commons Attribution Non-Commercial License (http://creativecommons.org/licenses/by-nc/3.0)

which permits unrestricted non-commercial use, distribution, and reproduction in any medium, provided the original work is properly cited. 

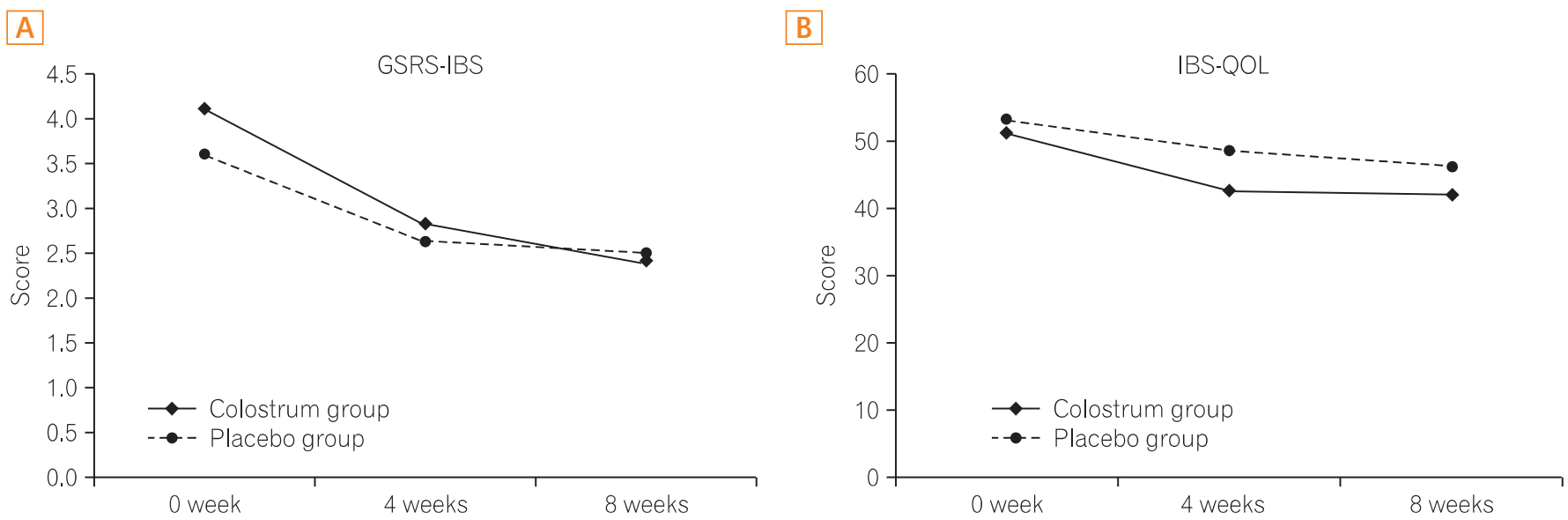

Fig. 1. Comparison of patients in the colostrum and placebo groups using (A) GSRS-IBS and (B) IBS-QOL. GSRS-IBS, gastrointestinal symptom rating scale-irritable bowel syndrome; IBS-00L, irritable bowel syndrome-quality of life.

metric properties. ${ }^{13}$ This questionnaire included the rating of 13 problems such as satiety, abdominal pain, diarrhea, constipation, and bloating on a 7-point Likert scale ranging from 1 (good status) to 7 (bad status). Data were collected every 2 weeks. The third scoring index was the assessment of the quality of life (QOL), by using the IBS-QOL questionnaire, which comprised 34 questions relating to the symptoms of IBS before treatment (week 0), at the end of colostrum administration (week 4), and at the end of the study (week 8). ${ }^{14}$ The third scoring index is the most extensively validated of all QOL measures, which has accurate psychometric and methodological qualities. ${ }^{15,16}$ Endotoxin levels obtained through blood sampling at weeks 0,4 , and 8 were used as a secondary outcome variable.

A total of 18 patients with IBS were randomly classified into the colostrum group $(n=9)$ and placebo group $(n=9)$. Primary analysis by using the IBS-GIS revealed a slightly higher rate of symptom relief in the colostrum group (55.5\%) than the placebo group (44.4\%) at 4 weeks, but this difference was not significant. The mean symptom score obtained using the GSRS-IBS analysis decreased by 1.3 points (from 4.1 to 2.8 ) in the colostrum group and 1.0 point (from 3.6 to 2.6) in the placebo group at 4 weeks, and decreased by 1.7 points (from 4.1 to 2.4 ) in the colostrum group and 1.1 points (from 3.6 to 2.5 ) in the placebo group at 8 weeks (Fig. 1A). The interval change of this score was not statistically different between the 2 groups at both 4 and 8 weeks. The IBS-QOL analysis, which was converted to a $0-100$ scale ranging from 0 (poor quality of life) to 100 (maximum quality of life), revealed that both the groups rather made a little change for the worse. The IBSQOL score of the colostrum group diminished by 8.8 points at 4 weeks and 9.1 points at 8 weeks, and that of the control group diminished by 4.7 points at 4 weeks and 6.3 points at 8 weeks (Fig. 1B). The overall IBS-QOL score was not statistically different between the 2 groups.

After 4 weeks (i.e. immediately after treatment), the en-

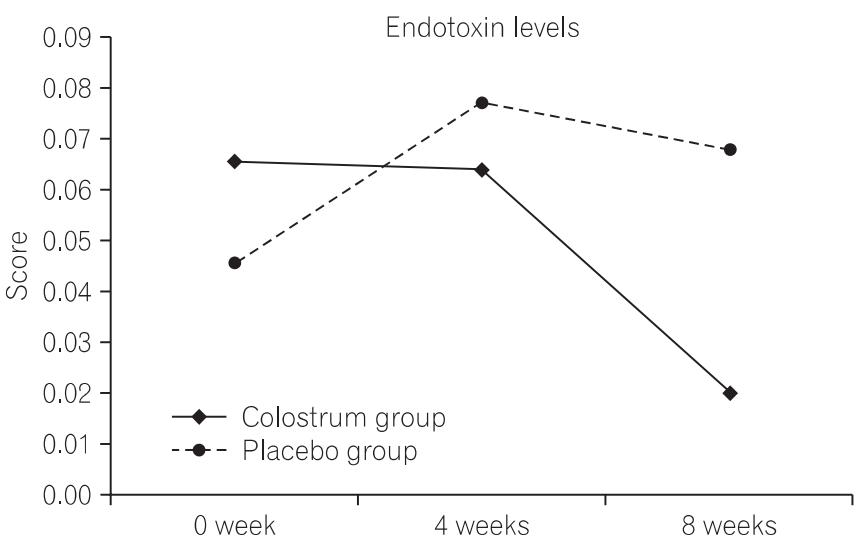

Fig. 2. Comparison of the changes in the endotoxin level between patients in the colostrum and placebo groups.

dotoxin levels of patients in the colostrum group showed a decrease in $44.4 \%(4 / 9)$ patients, no interval change in $11.1 \%(1 / 9)$ patients, and an increase in $44.4 \%(4 / 9)$ patients. The endotoxin levels of patients in the placebo group did not show any decrease; however, no interval change in the endotoxin levels was observed in $33.3 \%$ (3/9) patients, and an increase in $66.6 \%$ (6/9) patients. After 8 weeks (i.e. after observation period), the endotoxin levels of patients in the colostrum group showed a decrease in $33.3 \%$ (3/9) patients, no interval change in $44.4 \%$ (4/9) patients, and an increase in $22.2 \%(2 / 9)$ patients. The endotoxin levels of patients in the placebo group showed a decrease in $11.1 \%(1 / 9)$ patients, no interval change in $33.3 \%$ (3/9) patients, and an increase in $55.5 \%(5 / 9)$ patients. Although patients in the colostrum group appeared to have a greater improvement in the endotoxin levels as evaluated using categorical analysis, there was no significant difference in the interval change of the calculated endotoxin value between the 2 groups using a repeated analysis of variance test (Fig. 2). 
A limitation of this study was the small sample size.

In conclusion, this study showed that colostrum had no benefits in relieving symptoms and improving mucosal immunity of patients with IBS. The response rate of patients in the placebo group is crucial in therapeutic trials conducted to evaluate IBS. The placebo response rates have ranged from $16.0-71.4 \%$ with a population-weighted average of $40.2 \%$ in randomized placebo-controlled trials of patients with IBS. ${ }^{17}$ This high placebo response rate could also confirm the lack of any significant benefits of colostrum in patients with IBS. ${ }^{18}$ Therefore, further large-scale studies to demonstrate the usefulness of colostrum are required.

\section{REFERENCES}

1. Drossman DD, Corazziari E, Delvaux M, et al. Rome III: the functional gastrointestinal discorders. 3rd ed. McLean, VA: Degnon Associates, Inc., 2006.

2. Park KS, Ahn SH, Hwang JS, et al. A survey about irritable bowel syndrome in South Korea: prevalence and observable organic abnormalities in IBS patients. Dig Dis Sci 2008;53:704-711.

3. Kirsch R, Riddell RH. Histopathological alterations in irritable bowel syndrome. Mod Pathol 2006;19:1638-1645.

4. Chadwick VS, Chen W, Shu D, et al. Activation of the mucosal immune system in irritable bowel syndrome. Gastroenterology 2002;122:1778-1783.

5. van Deventer SJ, ten Cate JW, Tytgat GN. Intestinal endotoxemia. Clinical significance. Gastroenterology 1988;94:825-831.

6. Liebregts T, Adam B, Bredack C, et al. Immune activation in patients with irritable bowel syndrome. Gastroenterology 2007;132:913-920.

7. Uruakpa FO, Ismond MAH, Akobundu ENT. Colostrum and its benefits: a review. Nutrition Research 2002;22:755-767.

8. Pakkanen R. Determination of transforming growth factor-beta 2 (TGF-beta 2) in bovine colostrum samples. J Immunoassay
1998;19:23-37.

9. Playford RJ, Macdonald CE, Johnson WS. Colostrum and milkderived peptide growth factors for the treatment of gastrointestinal disorders. Am J Clin Nutr 2000;72:5-14.

10. Rawal P, Gupta V, Thapa BR. Role of colostrum in gastrointestinal infections. Indian J Pediatr 2008;75:917-921.

11. Longstreth GF, Thompson WG, Chey WD, Houghton LA, Mearin F, Spiller RC. Functional bowel disorders. Gastroenterology 2006;130:1480-1491.

12. Gordon S, Ameen V, Bagby B, Shahan B, Jhingran P, Carter E. Validation of irritable bowel syndrome Global Improvement Scale: an integrated symptom end point for assessing treatment efficacy. Dig Dis Sci 2003;48:1317-1323.

13. Wiklund IK, Fullerton S, Hawkey CJ, et al. An irritable bowel syndrome-specific symptom questionnaire: development and validation. Scand J Gastroenterol 2003;38:947-954.

14. Patrick DL, Drossman DA, Frederick IO, DiCesare J, Puder KL. Quality of life in persons with irritable bowel syndrome: development and validation of a new measure. Dig Dis Sci 1998;43:400411.

15. Bijkerk CJ, de Wit NJ, Muris JW, Jones RH, Knottnerus JA, Hoes AW. Outcome measures in irritable bowel syndrome: comparison of psychometric and methodological characteristics. Am J Gastroenterol 2003;98:122-127.

16. Park JM, Choi MG, Oh JH, et al. Cross-cultural validation of irritable bowel syndrome quality of life in Korea. Dig Dis Sci 2006;51:1478-1484.

17. Patel SM, Stason WB, Legedza A, et al. The placebo effect in irritable bowel syndrome trials: a meta-analysis. Neurogastroenterol Motil 2005; 17:332-340.

18. Kellow J, Lee OY, Chang FY, et al. An Asia-Pacific, double blind, placebo controlled, randomised study to evaluate the efficacy, safety, and tolerability of tegaserod in patients with irritable bowel syndrome. Gut 2003;52:671-676. 